\title{
Neuropathic Pain: Redundant Pathways, Inadequate Therapy
}

Can J Neurol Sci. 2012; 39: 409-410

In this issue of Canadian Journal of Neurological Sciences (CJNS), Patrick Stemkowski and Peter Smith provide a timely, comprehensive and informative review of mechanisms of neuropathic pain ${ }^{1}$. From a laboratory that houses Canadian and internationally recognized expertise on the physiological mechanisms of pain, the authors elegantly describe the alterations in membrane properties of sensory neurons in dorsal root ganglia, the parent cell bodies of sensory axons that innervate the skin, muscles and viscera. One of the fascinating aspects of sensory neuron biology is in understanding how cell body mRNA transcription and protein synthesis interact with events in sensory neuron terminals. New data, for example, by Twiss, Willis and colleagues ${ }^{2}$ suggest a new locus of mRNA translation-the axon itself, hosting mRNAs and translational machinery capable of altering the local axon proteonome. During injury, disease or during the development and sustenance of neuropathic pain, this local machinery may interact in interesting ways with the mRNA and protein output of the cell body, transported down axons to terminals. From the work of Verge, Hokfelt and others ${ }^{3,4}$ we also know that the entire neuronal tree is fundamentally altered by injury and inflammation, changing the repertoire of membrane expressed proteins. Not only does the cell body alter its properties, but perineuronal satellite cells, intimately surrounding and communicating with sensory neurons enlarge and proliferate, influencing neuronal events. Careful, rigorous and comprehensive analysis of these changes that alter neuronal excitability, and the propagation of inappropriate pain discharges, as described by the authors, reflect a combination of injury and inflammation related events.

Multiple sites in the nervous system participate in the development of neuropathic pain. The repertoire of peripherally acting algesic, or pain generating, molecules elaborated at sites of injury (including the injured nerve trunk) are now known to include NGF and nitric oxide in addition to protons, potassium ions, histamine and many others. Specific alterations in the channel properties of axon terminals at the level of the injury likely ensue, associated with the changes in the cell body discussed above. In addition to events that primarily involve the sensory neuron however, the critical relay sites of sensory information are also fundamentally altered in neuropathic pain. This is also an important Canadian story, involving work by the Salter and De Koninck laboratories in Toronto and Quebec City respectively ${ }^{5}$. At the level of the dorsal horn of the spinal cord, it is now known that the intrinsic glial inflammatory cells of the CNS, microglia, are activated and increase their expression of inflammation-related proteins including $\mathrm{P} 2 \mathrm{X} 4$ receptors and the second messenger p38 MAP kinase ${ }^{6}$ Microglia dampen dorsal horn inhibitory mechanisms or facilitate excitation through the release of $\mathrm{BDNF}^{5,7}$ that act on lamina I neurons of the dorsal horn through TrkB receptors to in turn suppress KCC2 chloride transporters. This suppression increases intraneuronal $\mathrm{Cl}$ - levels, a change that promotes neuropathic pain through a change in neuronal phenotype.

We also now know that the several other higher CNS loci have a critical role in the generation of neuropathic pain, such as the cingulate gyrus; work by Zhuo and colleagues, also from Toronto, was highlighted in a previous review article in CJNS in $2005^{8}$. Anterior cingulate gyrus neurons develop long-term potentiation and depression, mediated through alterations in glutamate receptor signaling, NMDA (N-methyl-D-aspartate) receptors and calcium-calmodulin activated adenylyl cyclases, processes that resemble those involved in memory in the hippocampus ${ }^{8}$. For a beautiful review of the neuroanatomy of pain, please also see the paper published by Arthur Hudson, from London, Ontario, in CJNS 9 .

The unravelling of multiple and redundant pathways involved in the generation of neuropathic pain: neuroanatomical, cellular and molecular, provides a wide range of new opportunities to treat it. Regrettably however, the armamentarium is limited in scope and the benefits of individual agents are incomplete. The range of differing phenotypes and etiologies of neuropathic pain in neurological practice is extensive, giving pause to those who think that quick fixes are imminent. A new definition by Treede and colleagues ${ }^{10}$ has been helpful and I would direct readers to it. Dr. Claudia Sommer from the University of Wurzburg and I have had the opportunity of compiling some of our collective experiences with neurological pain, soon to be published by Cambridge [Case Studies in Neurological Pain] ${ }^{11}$ and the overall message remains challenging. Patients frequently fail first line therapies, have therapy complicated by multiple medical comorbidities, or are intolerant of the side effects from the agents available. Despite this pessimistic outlook, several new guidelines are available to help the clinician decide among current therapies for neuropathic pain. Prominent among these are those recently published by the American Academy of Neurology (AAN), an extensive effort spearheaded by Dr. Vera Bril from Toronto $^{12}$. These guidelines give a Level A recommendation for the use of pregabalin as first line therapy for neuropathic pain. Level B recommendations (probably effective) were given for gabapentin, sodium valproate, amitriptyline, venlafaxine, duloxetine, dextromethorphan, morphine sulphate, tramadol, oxycodone, capsaicin, isorbide dinitrate and percutaneous electrical stimulation. Other guidelines differ somewhat, most frequently giving higher recommendations to duloxetine than do the AAN guidelines. ${ }^{13,14}$

It is clear that ongoing expertise and attention toward the problems of neuropathic pain will be essential to deal with this massive and growing health issue ${ }^{15}$. Neurology divisions and departments need to support and develop interdisciplinary 
neurology pain programs: while our tools are limited, current guidelines do offer important guidance for clinicians, provided we can develop a sufficient cohort of colleagues who can apply and improve them.

\section{Douglas Zochodne Department of Clinical Neurosciences and the Hotchkiss Brain Institute University of Calgary, Calgary, Alberta, Canada}

\section{REFERENCES}

1. Stemkowski PL, Smith PA. Sensory neurons, ion channels, inflammation and the onset of neuropathic pain. Can J Neurol Sci. 2012;39(4):416-35.

2. Willis DE, Twiss JL. The evolving roles of axonally synthesized proteins in regeneration. Curr Opin Neurobiol. 2006 Feb;16: $111-18$.

3. Zhang X, Meister B, Elde R, Verge VMK, Hokfelt T. Large calibre primary afferent neurons projecting to the gracile nucleus express neuropeptide $\mathrm{Y}$ after sciatic nerve lesions: an immunohistochemical and in situ hybridization study in rats. Eur J Neurosci. 1993;5:1510-19.

4. Verge VMK, Gratto KA, Karchewski LA, Richardson PM. Neurotrophins and nerve injury in the adult. Philos Trans R Soc Lond B Biol Sci. 1996;351:423-30.

5. Coull JA, Beggs S, Boudreau D, et al. BDNF from microglia causes the shift in neuronal anion gradient underlying neuropathic pain. Nature. 2005 Dec 15;438:1017-21.
6. Tsuda M, Inoue K, Salter MW. Neuropathic pain and spinal microglia: a big problem from molecules in "small" glia. Trends Neurosci. 2005 Feb;28:101-7.

7. Beggs S, Salter MW. Microglia-neuronal signalling in neuropathic pain hypersensitivity 2.0. Curr Opin Neurobiol. 2010 Aug;20: 474-80.

8. Zhuo M. Canadian Association of Neuroscience review: cellular and synaptic insights into physiological and pathological pain. EJLB-CIHR Michael Smith Chair in Neurosciences and Mental Health lecture. Can J Neurol Sci. 2005 Feb;32:27-36.

9. Hudson AJ. Pain perception and response: central nervous system mechanisms. Can J Neurol Sci. 2000 Feb;27:2-16.

10. Treede RD, Jensen TS, Campbell JN, et al. Neuropathic pain: redefinition and a grading system for clinical and research purposes. Neurology. 2008 Apr 29;70:1630-5.

11. Sommers CJ, Zochodne DW. Case studies in neurological pain. Cambridge Press, 2012 [in press].

12. Bril V, England J, Franklin GM, et al. Evidence-based guideline: treatment of painful diabetic neuropathy: report of the American Academy of Neurology, the American Association of Neuromuscular and Electrodiagnostic Medicine, and the American Academy of Physical Medicine and Rehabilitation. Neurology. 2011 May 17;76:1758-65.

13. Dworkin RH, O'Connor AB, Audette J, et al. Recommendations for the pharmacological management of neuropathic pain: an overview and literature update. Mayo Clin Proc. 2010 Mar;85: S3-14.

14. Attal N, Cruccu G, Haanpaa M, et al. EFNS guidelines on pharmacological treatment of neuropathic pain. Eur J Neurol. 2006 Nov;13:1153-69.

15. Toth C, Lander J, Wiebe S. The prevalence and impact of chronic pain with neuropathic pain symptoms in the general population. Pain Med. 2009 Jul;10:918-29. 